\title{
A Ce-Nd-Hf isotope perspective on the EMI-EMII end-member
}

\author{
RÉGIS DOUCELANCE ${ }^{1}$, CLAUDINE ISRAEL ${ }^{1}$, MAUD \\ BOYET $^{1}$, PIERRE BONNAND ${ }^{1}$, MATTHEW G. JACKSON ${ }^{2}$ \\ AND JANE BARLING ${ }^{3}$ \\ ${ }^{1}$ Laboratoire Magmas et Volcans, Université Clermont-Auvergne \\ ${ }^{2}$ University of California, Santa Barbara \\ ${ }^{3}$ Oxford University \\ Presenting Author: regis.doucelance@uca.fr
}

Strontium- $\mathrm{Nd}-\mathrm{Pb}$ isotopic compositions measured in ocean island basalts (OIB) have led to the definition of several mantle end-members referred to as HIMU, EMI and EMII. Their isotope signatures are thought to be inherited from the recycling of surface materials but no consensus has been reached about their exact nature or age of recycling. In particular, EM-like compositions are generally proposed to be related to the recycling of either pelagic and/or terrigeneous sediments in the mantle source of OIB, or to the subduction of oceanic plates or delamination of sub-continental materials.

In this study we combine the Lanthanum-Cerium and Samarium-Neodymium isotope systematics in order to reconstruct the LREE pattern of recycled material incorporated into the OIB source. Cerium is a redox sensitive element and its valence changes from $\mathrm{Ce} 3+$ to $\mathrm{Ce} 4+$ under oxidized conditions (e.g. oceans). This results in increased $\mathrm{La} / \mathrm{Ce}$ ratios in oceanic sediments, which, with time, lead to more radiogenic Ce isotopic compositions than those of continent-derived material with similar $\mathrm{Nd}$ isotopic compositions. Oceanic sediments formed before the Great Oxidation Event (GOE - 2.0-2.4 Ga [1]) however should be devoid of $\mathrm{Ce}$ anomalies.

We present the first Ce isotope analyses of samples from the Samoa archipelago (EMII-like) together with new Hf-Nd data and compare them with those of EMI-like basalts from Gough, Heard and Tristan Da Cunha Islands [2,3,4]. Samoa shows Ce$\mathrm{Nd}-\mathrm{Hf}$ isotopic compositions covering most of the mantle array, whereas Gough and Tristan da Cunha display a similar range of $\varepsilon \mathrm{Ce}$ values for a smaller range of $\varepsilon \mathrm{Nd}$ and $\varepsilon \mathrm{Hf}$. Mixing models show that the pre-GOE recycling of subducted oceanic crust and overlying sediments best reproduces the three sets of EM-1 OIB compositions, while EM-2-like samples from Samoa can be explained by addition of post-GOE sediments to a FOZO-like mantle.

[1] Holland (2002) GCA 66, 3811-3826 ; [2] Boyet et al. (2019) G-cubed 20 ; [3] Israel et al. (2020) EPSL 530, 115941 ;

[4] Willig et al. (2020) GCA 272, 36-53 